\title{
Stress and Chytridiomycosis:
}

Exogenous Exposure to

Corticosterone Does not Alter

Amphibian Susceptibility to a Fungal Pathogen

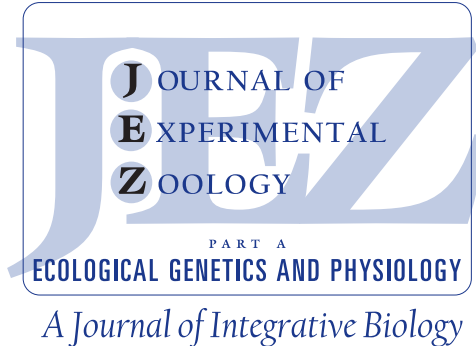

A Journal of Integrative Biology

\section{CATHERINE L. SEARLE ${ }^{1,2 *}$, LISA K. BELDEN ${ }^{3}$, PANG DU ${ }^{4}$,} AND ANDREW R. BLAUSTEIN ${ }^{2}$

${ }^{1}$ Department of Ecology and Evolutionary Biology, University of Michigan, Ann Arbor, Michigan

${ }^{2}$ Department of Zoology, Oregon State University, Corvallis, Oregon

${ }^{3}$ Department of Biological Sciences, Virginia Tech, Blacksburg, Virginia

${ }^{4}$ Department of Statistics, Virginia Tech, Blacksburg, Virginia

ABSTRACT
Recent emergence and spread of the amphibian fungal pathogen, Batrachochytrium dendrobatidis
(Bd) has been attributed to a number of factors, including environmental stressors that increase
host susceptibility to Bd. Physiological stress can increase circulating levels of the hormone,
corticosterone, which can alter a host's physiology and affect its susceptibility to pathogens. We
experimentally elevated whole-body levels of corticosterone in both larval and post-metamorphic
amphibians, and subsequently tested their susceptibility to Bd. Larvae of three species were tested
(Anaxyrus boreas, Rana cascadae, and Lithobates catesbeianus) and one species was tested after
metamorphosis ( $R$. cascadae). After exposure to Bd, we measured whole-body corticosterone,
infection, mortality, growth, and development. We found that exposure to exogenous
corticosterone had no effect on Bd infection in any species or at either life stage. Species varied
in whole-body corticosterone levels and exposure to corticosterone reduced mass in A. boreas and
R. cascadae larvae. Exposure to Bd did not affect mortality, but had a number of sublethal effects.
Across species, larvae exposed to Bd had higher corticosterone levels than unexposed larvae, but the
opposite pattern was found in post-metamorphic $R$. cascadae. Bd exposure also increased larval
length in all species and increased mass in $R$. cascadae larvae. Our results indicate that caution is
warranted in assuming a strong link between elevated levels of corticosterone and disease
susceptibility in amphibians. The role of physiological stress in altering Bd prevalence in amphibian
populations is likely much more complicated than can be explained by examining a single "stress"
endpoint. J. Exp. Zool. 321A:243-253, 2014. C 2014 Wiley Periodicals, Inc.
How to cite this article: Searle CL, Belden LK, Du P, Blaustein AR. 2014. Stress and
chytridiomycosis: Exogenous exposure to corticosterone does not alter amphibian susceptibility
to a fungal pathogen. J. Exp. Zool. 321A:243-253.

Grant sponsor: Graduate Women in Science Sigma Delta Epsilon Fellowship; grant sponsor: Society of Wetland Scientists; grant sponsor: Environmental Sciences Graduate Program at Oregon State University; grant sponsor: National Science Foundation; grant number: DEB-0918960. Conflicts of interest: None.

${ }^{*}$ Correspondence to: Catherine L. Searle, Department of Ecology and Evolutionary Biology, University of Michigan, 2019 Kraus Natural Sciences Building, Ann Arbor, MI 48109-1048.

E-mail: searlec@umich.edu
Received 26 March 2013; Revised 19 December 2013; Accepted 15 January 2014

DOI: $10.1002 /$ jez.1855

Published online 9 March 2014 in Wiley Online Library (wileyonlinelibrary.com). 
Infectious diseases are a growing global concern, particularly when epidemics result in population declines or reduced biodiversity (e.g., Daszak, 2000; Anderson et al., 2004). Globally, epidemics are increasing in both humans and wildlife (Harvell et al., 2002; Jones et al., 2008) and may be facilitated by anthropogenic changes to the environment. Environmental changes including pollution, invasive species, climate change, and habitat destruction can alter disease dynamics and shift hostpathogen relationships in complex and unpredictable ways (Patz et al., 2000; Daszak et al., 2001; Jones et al., 2008; Martin et al., 2010).

For hosts, environmental changes may act as stressors, modifying host behavior and physiology. Romero et al. (2009) define two normal reactive states for organisms: (1) predictive homeostasis, defined as the range of states encompassing circadian and seasonal variation and (2) reactive homeostasis, defined as the range needed to respond to unpredictable or threatening environmental changes. Unexpected environmental changes can push an individual into the reactive homeostasis range which can alter their physiology and affect interactions with other organisms such as pathogens. In vertebrates, the immediate stress response is regulated by catecholamines (e.g., epinephrine and norepinephrine) that are released within seconds of exposure to a stressful situation. However, after longer periods in reactive homeostasis (minutes to days), glucocorticoids (e.g., corticosterone and cortisol) are released from the adrenal cortex in response to a complex cascade involving the hypothalamus-pituitaryadrenal axis. Glucocorticoids have many actions in vertebrates, but they generally suppress non-vital functions and mobilize energy stores necessary for immediate survival (Romero, 2002). At chronic levels, glucocorticoids can inhibit functions like reproduction and immunity (Cohn, '97; Dhabhar, 2000; Tilbrook et al., 2000; French et al., 2007).

Elevation of glucocorticoids may be harmful if maintained in the homeostatic overload range (defined by Romero et al. [2009] as the physiological range above the normal reactive scope into a pathological state). For example, there is evidence that the ability to reduce glucocorticoid levels after a stressful event can be beneficial for survival in marine iguanas (Romero and Wikelski, 2010). It is interesting to note that many of the studies addressing the immune impacts of chronic elevation of glucocorticoids have been completed with humans, non-human primates, or common laboratory rodents. Relatively few studies have demonstrated chronic alteration of glucocorticoids in freeliving animals (Norris et al., '99; Cyr and Romero, 2007), perhaps because in nature there is strong selection against chronic elevation, which would reduce fitness. In fact, some studies attempting to induce elevated glucocorticoids through various stressors have failed to observe sustained hormone elevation (Cyr et al., 2007; Kostelanetz et al., 2009; Reeve et al., 2013). Even fewer studies have linked elevated glucocorticoid levels to altered disease susceptibility in wildlife. Nevertheless, understanding the potential links between chronic stress, elevation of glucocorticoids, and disease susceptibility remains a pressing area of research in the context of global change.

Elevation of glucocorticoids has been demonstrated in a number of organisms in response to experimentally induced stress. In amphibians, the main stress hormone is corticosterone, which plays a role in the timing and initiation of amphibian metamorphosis (Denver, '97; Hayes, '97), an aspect of predictive homeostasis. Corticosterone levels generally increase during late larval stages until reaching a peak during metamorphic climax, followed by a slow decline (Kloas et al., '97; Glennemeier and Denver, 2002a; Chambers et al., 2011). Amphibians will also elevate corticosterone into a reactive homeostasis range in response to stimuli, but these responses can vary with life stage (Crespi and Denver, 2005). In larvae, corticosterone can be elevated in response to crowding, food deprivation (Glennemeier and Denver, 2002c; Crespi and Denver, 2005), confinement (Glennemeier and Denver, 2002a; Belden et al., 2010), and acidic conditions (Chambers et al., 2013). Corticosterone elevation at the larval stage can lead to altered growth and development (Glennemeier and Denver, 2002b) and increased susceptibility to infectious disease (Belden and Kiesecker, 2005). Additionally, amphibian larvae treated with exogenous corticosterone can experience decreased circulating eosinophils and lymphocytes (Rollins-Smith and Blair, '93; Belden and Kiesecker, 2005). After metamorphosis, corticosterone can decrease in response to food deprivation (Crespi and Denver, 2005) and increase with habitat fragmentation (Janin et al., 2011), leading to decreased reproductive activity (Moore and Miller, '84). Additionally, environmental changes such as pollution can increase corticosterone at both life stages (Hopkins et al., '99; Hayes et al., 2006; Peterson et al., 2009). Two previous studies have found that stressors including predator cues, food deprivation and high densities did not increased ranavirus infection in amphibian larvae (Haislip et al., 2012; Reeve et al., 2013). However, elevated corticosterone at the larval stage can increase trematode infection (Belden and Kiesecker, 2005). Thus, the relationship between corticosterone and infection in amphibians may vary depending on the host and pathogen species.

One amphibian pathogen that has received considerable attention in the last decade is Batrachochytrium dendrobatidis (Bd; Berger et al., '98; Longcore et al., '99). Bd only infects keratinized structures of amphibians, which are present in mouthparts of larvae and the skin of post-metamorphic amphibians. Both lethal and sublethal effects of Bd infection have been documented in larval and post-metamorphic stages (e.g., Blaustein et al., 2005; Carey et al., 2006; Searle et al., 2011a). In postmetamorphic amphibians, innate responses to $\mathrm{Bd}$ infection, such as anti-microbial peptides and natural microbial skin assemblages, may provide some resistance to infection (RollinsSmith et al., 2002; Harris et al., 2006; Woodhams et al., 2007; Lam et al., 2010). However, there is little evidence that post-metamorphic 
amphibians have adaptive immune responses to $\mathrm{Bd}$ (Ribas et al., 2009; Rosenblum et al., 2009; Stice and Briggs, 2010; but see Ramsey et al., 2010). Even less is known about the larval immune response to $\mathrm{Bd}$, although poor diet has been shown to increase prevalence of larval infection (Venesky et al., 2012) and infected larvae experience altered white blood cell counts and increased corticosterone levels (Davis et al., 2010; Gabor et al., 2013). It has been suggested that increased susceptibility to $\mathrm{Bd}$ from environmental stressors may be one reason that it has globally increased its range and prevalence (e.g., Rollins-Smith et al., 2002; Garcia et al., 2006).

We tested the effects of exogenous corticosterone exposure on susceptibility to Bd using a comparative framework with the larvae of Anaxyrus boreas, Rana cascadae, and Lithobates catesbeianus and with post-metamorphic $R$. cascadae. Corticosterone can be artificially elevated in larval amphibians by adding exogenous hormone to water, where it is absorbed through their skin and gills. We exposed animals to exogenous corticosterone for 2 weeks before challenging them with Bd. By using exogenous corticosterone, we can identify how physiological stress may affect susceptibility without altering other aspects of the Bdamphibian relationship (e.g., transmission, pathogen virulence).

\section{MATERIALS AND METHODS}

\section{Animal Collection and Husbandry}

Amphibian eggs were collected from natural oviposition sites in the Willamette Valley and Cascades Mountain Range of Oregon, USA. Details of collection and rearing conditions are included in the supplemental materials (S-Methods). These species were chosen because they exhibit a range of susceptibility to $\mathrm{Bd}$, with $A$. boreas experiencing high rates of mortality at the larval and post-metamorphic stages (Blaustein et al., 2005; Carey et al., 2006) and L. catesbeianus identified as a species tolerant of Bd infection (Daszak et al., 2004; Blaustein et al., 2005). Additionally, $R$. cascadae can maintain lower levels of infection than the other two species at both life stages (Searle et al., 2011b; Gervasi et al., 2013). The mechanism for these differences in infection patterns is unknown. Experiment 1 used early-stage larvae and individuals used in experiment 1 were not used in experiment 2. Experiment 2 used post-metamorphic $R$. cascadae that had completed metamorphosis approximately 4 months prior to the start of the experiment. This study was conducted in accordance with Oregon State University's Institutional Animal Care and Use Committee.

\section{Experiment 1: Larval Amphibians}

Experiment 1 tested the effects of corticosterone on larval amphibians using all three species. Species were not tested concurrently, but the same protocol was used for each species and they were tested at the same developmental stage (stages 25-26; Gosner, '60). Larvae were held individually in $1 \mathrm{~L}$ plastic containers filled with $500 \mathrm{~mL}$ dechlorinated water for the duration of the experiment. Each species was tested with a $2 \times 4$ factorial design with two pathogen treatments and four levels of corticosterone (Sigma-Aldrich, St. Louis, MO, USA, product \#C2505). The two pathogen treatments were control (unexposed) and $\mathrm{Bd}$-exposed. Corticosterone treatments were (1) water control (30 $\mu \mathrm{L}$ dechlorinated water added to each $500 \mathrm{~mL}$ container), (2) ethanol control (30 $\mu \mathrm{L}$ of 95\% ethanol in each container), (3) low corticosterone $(0.01 \mu \mathrm{M}$ solution [0.00000173 g dissolved in $30 \mu \mathrm{L}$ of 95\% ethanol in each container]), and (4) high corticosterone (0.1 $\mu \mathrm{M}$ solution [0.0000173 $\mathrm{g}$ dissolved in $30 \mu \mathrm{L}$ of $95 \%$ ethanol in each container]). The ethanol control was included to ensure that patterns found in our corticosterone treatments were not due to the ethanol, into which corticosterone was dissolved. Treatment with exogenous corticosterone at these levels elevates whole-body corticosterone above the baseline levels naturally occurring in amphibians (Belden et al., 2005, 2010). Individuals were randomly assigned to treatments, with each treatment replicated 20 times for a total of 160 individuals for each species. Larvae were first exposed to corticosterone treatments for 15 days prior to $\mathrm{Bd}$ exposure. Previous studies have demonstrated immunosuppressive effects of corticosterone in vertebrates after as few as 5 days (Martin et al., 2005; Kiank et al., 2006). Water was changed every 3 days with corticosterone levels re-established at each water change (Fig. S1).

After 15 days of exposure to corticosterone treatments, animals were exposed to their $\mathrm{Bd}$ treatments three times during the subsequent 15 days (Fig. S1). Bd culturing and inoculation methods are described in the supplemental materials (S-Methods). Corticosterone exposures were maintained throughout this infection period with water changes every 3 days. Mortality was monitored daily and any dead animals were removed and preserved in 95\% ethanol. The experiment was terminated after 30 days, 2 days after the last corticosterone exposure (Fig. S1). Five animals from each treatment were flash-frozen for corticosterone analysis after being immersed in buffered MS-222 for less than $60 \mathrm{sec}$. For $L$. catesbeianus, only four animals were tested for corticosterone in the water control, Bd-exposed treatment. The remaining 10-15 animals/treatment (depending on mortality) were euthanized in MS-222 and then weighed, measured (snout-vent length), staged (Gosner, '60), and preserved in 95\% ethanol until infection analysis.

\section{Experiment 2: Post-Metamorphic Amphibians}

Experiment 2 tested the effects of corticosterone on postmetamorphic $R$. cascadae. This experiment was a $2 \times 2$ design with two treatments of $\mathrm{Bd}$ (exposed or unexposed) and two treatments of corticosterone (exposed or unexposed). There were 15 individuals in the $\mathrm{Bd}$-exposed treatments and 5 individuals in our Bd-control (unexposed) treatments for a total of 40 animals. The mass and length (snout-vent) of each animal was recorded at the beginning of the experiment before placing the animals in 
Petri dishes $\left(140 \times 30 \mathrm{~mm}^{2}\right)$ with holes in the lid and a paper towel covering the bottom. The corticosterone-exposed treatment was administered by adding $15 \mathrm{~mL}$ of a $0.5 \mu \mathrm{M}$ corticosterone solution (created by dissolving $2.595 \times 10^{-6} \mathrm{~g}$ corticosterone in $4.5 \mu \mathrm{L}$ of $95 \%$ ethanol in $15 \mathrm{~mL}$ water) to the bottom of each animal's Petri dish to saturate the paper towel. Corticosterone-control animals were given a similar treatment, but without corticosterone in the ethanol ( $4.5 \mu \mathrm{L}$ of $95 \%$ ethanol in $15 \mathrm{~mL}$ water). Paper towels were changed and new solution added every day.

After 15 days of exposure to corticosterone treatments, animals were exposed twice to their Bd treatment (on days 15 and 16). The $\mathrm{Bd}$ was cultured as described in experiment 1 (S-Methods), and $2 \mathrm{~mL}$ of inoculum was placed onto the dorsal side of each exposed animal. With the two inoculations combined, each Bd-exposed animal was exposed to approximately $8.5 \times 10^{4}$ zoospores. After $\mathrm{Bd}$ exposure, we continued to monitor mortality for an additional 15 days with corticosterone treatments administered daily. We then euthanized all animals in buffered MS-222, measured their mass and length, and swabbed them ten times on the left ventral side using a sterile fine tipped swab (Medical Wire and Equipment, Corsham, United Kingdom). This process took no more than $70 \mathrm{sec}$ for each animal. Five individuals from each treatment were then flash-frozen for corticosterone analyses.

\section{Corticosterone Analyses}

Radioimmunoassay followed the procedures of Belden et al. (2003), with some minor modifications. Larval samples were run in two assays, one consisting of the $R$. cascadae and L. catesbeianus samples $(N=79)$ and one consisting of $A$. boreas samples $(N=40)$. The post-metamorphic $R$. cascadae were run in a third assay $(N=20)$. Detailed methods are included in the supplemental materials (S-Methods). The average intraassay variation for these assays was $10 \%$ and interassay variation was 25\%. Average extraction efficiency was 62\% (range 27-89\%). For the postmetamorphic assay, intraassay variation was $1 \%$ and average extraction efficiency was 42\% (range 26-49\%).

For larvae of each of the three species there were 1-2 individuals in the ethanol or water control treatments that were off the low end of the curve (too little hormone in sample to accurately quantify), and for $A$. boreas, there was one individual in the low corticosterone treatment off the low end of the curve. For $A$. boreas and $R$. cascadae in the high corticosterone treatments, 10/10 and 9/10 samples, respectively, were off the top of the curve (too much hormone in the sample to accurately assess). For L. catesbeianus, only a single individual in the high corticosterone treatment was off the top of the curve. For $R$. cascadae in experiment 2 (after metamorphosis) there was one individual in the corticosterone-exposed, Bd control treatment that was off the top of the curve. For individuals with values off the top of the standard curve, we know the values are high, but we cannot assess exactly how high. For individuals off the low end of the curve, we know the value is low, but we cannot assess exactly how low. All corticosterone levels were log-transformed prior to analysis.

\section{Infection Analyses}

We tested for $\mathrm{Bd}$ infection using quantitative polymerase chain reaction ( $\mathrm{qPCR}$ ) on all $\mathrm{Bd}$-exposed animals in both experiments, plus five randomly-chosen $\mathrm{Bd}$-control animals from each species in experiment 1 and three from experiment 2. QPCR methods followed those of Boyle et al. (2004), except we used $60 \mu \mathrm{L}$ Prepman Ultra (Applied Biosystems, Foster City, CA, USA) in DNA extractions instead of $40 \mu \mathrm{L}$. Whole mouthparts were excised for larvae, while swabs were used for post-metamorphic animals. Using qPCR allowed us to determine infection status of each animal (infected or uninfected) and the severity of Bd infection (the amount of Bd in an infected animal). To control for body size among species and treatments in our larval infection analysis, we recorded the quantity of nucleotides in each DNA extraction using a Nanodrop 1000 (Thermo Scientific, Waltham, MA, USA) and calculated the genome equivalents of Bd per nanogram mouthpart DNA in each sample. Thus, our "infection severity" data were in the form of $\mathrm{Bd}$ concentration (genome equivalents/nanogram mouthpart DNA; Searle et al., 2011b).

\section{Statistical Analyses}

All statistical analyses were performed in R (R Development Core Team, 2011). For experiment 1, mortality was compared among species and treatments with generalized linear models (GLMs) using a logit link. Animals that died before experimental takedown were included in mortality analyses, but were not included in the other analyses. Comparing among $\mathrm{Bd}$ and corticosterone treatments for each species, we analyzed mass, length, and developmental stage using two-way ANOVA including the interaction between $\mathrm{Bd}$ and corticosterone treatments, followed by Tukey's HSD tests. For infection status and severity, we only used data from the Bd-exposed groups and compared among corticosterone treatments and species. Infection status (infected or uninfected) was analyzed using a binomial GLM and logtransformed infection severity (including only individuals testing positive for infection) was analyzed using a Gaussian GLM.

For experiment 2, change in mass and length among $\mathrm{Bd}$ and corticosterone treatments was compared using a two-way ANOVA. All other analyses included only Bd-exposed animals. Infection prevalence was compared between corticosterone treatments using a Fisher's exact test and log-transformed infection severity was compared using a Wilcoxon rank sum test using only animals that tested positive for infection. For 10 animals from experiment 2, we had information on both corticosterone level and infection severity, and performed a Pearson's correlation on these two responses.

For both experiments, we were interested in determining if our corticosterone treatments successfully elevated whole-body levels of corticosterone. As described above, some samples in both 
experiments had hormone concentrations that fell below or above the endpoints of the standard curve (levels of accurate detection) for the assay. These "non-detect" data, with chemical concentrations below or above assay detection limits, represent a common example of censored data (Kent and Funk, 2004; Helsel, 2005a). We recently applied censored regression that explicitly accounts for "non-detect" observations (Helsel, 2005a, b) in two endocrine studies examining corticosterone concentrations in larval amphibians (Chambers et al., 2011, 2013). We follow a similar approach here for corticosterone comparisons (outlined in S-Methods). For these analyses, we used the SURVREG function in the SURVIVAL package in R 2.14.1 ( $R$ Development Core Team, 2011) that offers analyses parallel to standard ANOVA. For experiment 1, all the corticosterone levels of $A$. boreas samples and all but one $R$. cascadae sample in the high corticosterone treatment were right censored. Hence we decided to drop the high corticosterone treatment data from our analysis. However, the high corticosterone treatment was used in all other analyses. We then compared the corticosterone levels among all the species (for experiment 1), both Bd treatment groups, and the remaining corticosterone treatments. We first used the full model with these three factors and their interactions, and used a stepwise model selection procedure to find the most parsimonious model (command "stepAIC" in R, Crawley, 2007). Terms were dropped from the model and improvement was judged based on minimizing Aikaike's Information Criteria (AIC); if a term was dropped and there was negligible loss of explanatory power, the simplification was deemed appropriate. For experiment 2, our full model started with corticosterone treatment, Bd treatment and the interaction term.

\section{RESULTS}

Experiment 1: Larval Amphibians

Corticosterone did not influence larval infection with $\mathrm{Bd}$. In experiment 1, corticosterone treatment did not affect infection status or infection severity (status: $X^{2}=16.74, P=0.438$; severity:
$F_{2,90}=1.92, P=0.131$; Tables $\mathrm{S} 1$ and S2). However, infection status and severity differed by species (status: $X^{2}=16.74$, $P<0.001$; severity: $F_{2,90}=8.04, P=0.001$; Table 1 ). Larval $L$. catesbeianus had the highest infection prevalence, while $R$. cascadae had the highest infection severity (Table 1). We did not detect $\mathrm{Bd}$ on any of the tested unexposed larvae, indicating that our control treatments were uncontaminated. Mortality did not differ among species or treatments ( $P>0.05$ for all predictors), and survival was over $80 \%$ for all species (Table 1 ).

Our corticosterone treatments successfully elevated wholebody levels of corticosterone. The most parsimonious model for corticosterone levels included all potential factors and two-way interactions between species and corticosterone treatment and between corticosterone and $\mathrm{Bd}$ treatments. There were significant differences in corticosterone levels under different corticosterone treatments (corticosterone treatment, $P<0.001$, Table 2, Fig. 1). Specifically, levels were clearly higher under the low corticosterone treatment compared to the two control treatments. Although we were not able to include the high-corticosterone treatment in our analyses of corticosterone levels, that fact that most of our high-corticosterone treatment values were above the curve indicates that they were higher than levels in the other treatments. The differences in corticosterone levels across corticosterone treatments also depended on species (species $\times$ corticosterone treatment, $P=0.014$, Table 2, Fig. 1) and $\mathrm{Bd}$ treatments effect (corticosterone treatment $\times \mathrm{Bd}$ treatment, $P<0.001$, Table 2, Fig. 1). Samples from $A$. boreas had more folds of increase in corticosterone than samples of $R$. cascadae and L. catesbeianus. Individuals exposed to $\mathrm{Bd}$ had many more folds of increase in corticosterone than those in the $\mathrm{Bd}$ control groups, but only to a small degree in the low corticosterone treatment (Fig. 1, Table S3).

Exposure to corticosterone had a number of effects on life history traits including reduced length, mass, and development (Fig. 2). Comparing among all corticosterone treatments, $A$. boreas exposed to corticosterone were smaller (mass) and less developed at the end of the experiment relative to non-exposed individuals, but length was not affected (ANOVA; mass: $F_{3,87}=2.73, P=0.05$;

\begin{tabular}{|c|c|c|c|c|}
\hline $\begin{array}{l}\text { Species } \\
\text { (stage) }\end{array}$ & $\begin{array}{l}\text { Proportion } \\
\text { surviving }\end{array}$ & $\begin{array}{l}\text { Proportion } \\
\text { infected }^{\mathrm{a}}\end{array}$ & $\begin{array}{c}\text { Average } \\
\text { infection }\left(\mathrm{ge}^{\mathrm{b}} ; \mathrm{SE}\right)^{\mathrm{a}}\end{array}$ & $\begin{array}{c}\text { Average infection } \\
\text { severity (ge/ng ; SE) }\end{array}$ \\
\hline Anaxyrus boreas (larvae) & $0.85(136 / 160)$ & 0.50 & $5.2(1.9)$ & $0.08(0.03)$ \\
\hline Lithobates catesbeianus (larvae) & $0.92(147 / 160)$ & 0.85 & $9.4(1.5)$ & $0.07(0.01)$ \\
\hline Rana cascadae (larvae) & $0.84(135 / 160)$ & 0.61 & $26.4(6.3)$ & $0.26(0.06)$ \\
\hline Rana cascadae (juveniles) & $1.00(40 / 40)$ & 0.80 & $0.84(0.22)$ & - \\
\hline \multicolumn{5}{|c|}{$\begin{array}{l}\text { a Infection summaries were calculated using only Bd-exposed animals that survived to the end of the experiment. } \\
\text { bAverage infection is the amount of Bd detected in each sample (of those positive for infection) and is in units of genome equivalents of Bd. } \\
{ }^{c} \text { Average infection severity was calculated by dividing total infection of each individual by the concentration of DNA in each sample (of those positive for } \\
\text { infection) and is in the form of genome equivalents of Bd per nanogram mouthpart DNA. We used this measure of infection in our larval analyses since it } \\
\text { corrects for differences in body size. }\end{array}$} \\
\hline
\end{tabular}




\begin{tabular}{|c|c|c|c|c|}
\hline Experiment & Source & df & LRT statistic & $P$-Value \\
\hline \multirow[t]{5}{*}{ 1: Larval amphibians } & Species & 2 & 110.21 & $<0.001$ \\
\hline & Corticosterone treatment & 2 & 58.66 & $<0.001$ \\
\hline & Bd treatment & 1 & 11.15 & $<0.001$ \\
\hline & Species $\times$ corticosterone treatment & 4 & 12.51 & 0.014 \\
\hline & Corticosterone $\times \mathrm{Bd}$ treatment & 2 & 21.28 & $<0.001$ \\
\hline \multirow[t]{2}{*}{ 2: Post-metamorphic amphibians } & Corticosterone treatment & 1 & 4.44 & 0.035 \\
\hline & Bd treatment & 1 & 4.49 & 0.034 \\
\hline
\end{tabular}

length: $F_{3,87}=1.13, \quad P=0.34$; stage: $F_{3,87}=5.60, \quad P<0.01$; Fig. 2A,D,G). Similarly, for $R$. cascadae, corticosterone exposed individuals were smaller (mass) and shorter at the end of the experiment relative to non-exposed individuals, but development was unaffected (mass: $F_{3,87}=5.31, P<0.01$; length: $F_{3,87}=9.00$, $P<0.01$; stage: $F_{3,87}=0.79, P=0.50$; Fig. $\left.2 \mathrm{~B}, \mathrm{E}, \mathrm{H}\right)$. In contrast, mass, length, and stage were unaffected by corticosterone treatment in $L$. catesbeianus (mass: $F_{3,99}=0.13, P=0.94$; length: $F_{3,99}=0.12, P=0.95$; stage: $F_{3,99}=1.04, P=0.38$; Fig. $\left.2 \mathrm{C}, \mathrm{F}, \mathrm{I}\right)$.

Exposure to $\mathrm{Bd}$ increased larval length in all species and increased mass in one species (Fig. 2). In all species, individuals exposed to $\mathrm{Bd}$ were longer compared to unexposed individuals (ANOVA; A. boreas: $F_{1,87}=3.99, \quad P=0.05 ; \quad R$. cascadae: $F_{1,87}=7.74, P<0.01 ;$ L. catesbeianus: $F_{1,99}=4.14, P=0.04$; Fig. 2D-F). Individuals were heavier when exposed to $\mathrm{Bd}$ compared to unexposed individuals in $R$. cascadae $\left(F_{1,87}=3.92\right.$, $P=0.05$; Fig. 2B), but mass was unaffected by Bd treatment in the two other species (A. boreas: $F_{1,87}=0.86, P=0.36 ;$ L catesbeianus: $F_{1,99}=2.99, P=0.09$; Fig. $\left.2 \mathrm{~A}, \mathrm{C}\right)$. Developmental stage was unaffected by Bd treatment, although $L$. catesbeianus tended to be more developed when exposed to $\mathrm{Bd}$ compared to the unexposed individuals $\left(A\right.$. boreas: $F_{1,87}=0.15, P=0.70 ; R$. cascadae: $F_{1,87}=1.74, P=0.19 ;$ L. catesbeianus: $F_{1,99}=3.75, P=0.06$; Fig. 2G-I). The interaction between Bd treatment and corticosterone treatment was not a significant predictor of length, mass or development ( $P>0.05$ for all models).

\section{Experiment 2: Post-Metamorphic Amphibians}

There was no effect of corticosterone on post-metamorphic infection. In the Bd-exposed treatments, infection prevalence was $66.6 \%$ in the no-corticosterone treatments and $93.3 \%$ in the corticosterone-exposed treatments, but this difference was not significant $(P=0.17)$. Infection severity also did not differ among corticosterone treatments $(W(22)=62, P=0.66)$. Our method of corticosterone exposure successfully increased corticosterone levels ( $P=0.035$; Table 2; Fig. 3$)$ and corticosterone levels were lower in the Bd-exposed animals $(P=0.034$; Table 2; Fig. 3). Change in mass and change in length were not affected by either treatment $(P>0.05$ for all). There was no mortality during experiment 2 (Table 1) and no significant correlation between corticosterone levels and infection severity $(t=1.64, P=0.139$; Fig. S2).

\section{DISCUSSION}

We found that exposure to exogenous corticosterone did not alter Bd infection in larval or post-metamorphic amphibians. Even though we were able to successfully elevate corticosterone levels at both life stages (likely into homeostatic overload ranges in our high-corticosterone larval treatment), we did not find evidence for elevated infection compared to the treatments without corticosterone. While we did not measure immune responses, our results suggest that either the amphibian immune system is ineffective at reducing $\mathrm{Bd}$ infection, or our treatment of corticosterone did not alter aspects of the immune system associated with fighting Bd. In post-metamorphic amphibians, anti-microbial peptides and microbial skin assemblages can help fight $\mathrm{Bd}$ infection, but vary by species (Harris et al., 2006). Thus, it is possible that postmetamorphic $R$. cascadae have few natural defenses from $\mathrm{Bd}$. In larvae, an effective anti-Bd immune response has not been found, and it seems unlikely that larvae would invest large amounts of energy into fighting $\mathrm{Bd}$ since infection can be shed at metamorphosis as larval mouthparts are lost (Marantelli et al., 2004; Searle et al., 2013).

We also found that the effects of $\mathrm{Bd}$ exposure on corticosterone varied with life stage. In larvae, exposure to Bd increased wholebody levels of corticosterone, while the opposite pattern was found after metamorphosis. A number of studies have observed an increase in baseline or induced glucocorticoid levels with pathogen infection (e.g., Dunn et al., '89; Dunlap and Schall, '95; Raouf et al., 2006) which may be a mechanism for mobilizing resources to fight infection. In amphibians, Gabor et al. (2013) found that larvae infected with $\mathrm{Bd}$ had higher corticosterone release rates than uninfected larvae, and Warne et al. (2011) found that exposure to ranavirus increased corticosterone levels in amphibian larvae. Thus, elevating corticosterone levels may be a general response of amphibian larvae to infection. Alternatively, $\mathrm{Bd}$ infection in larval mouthparts can impair feeding (Venesky et al., 2010), and food restriction can increase corticosterone 

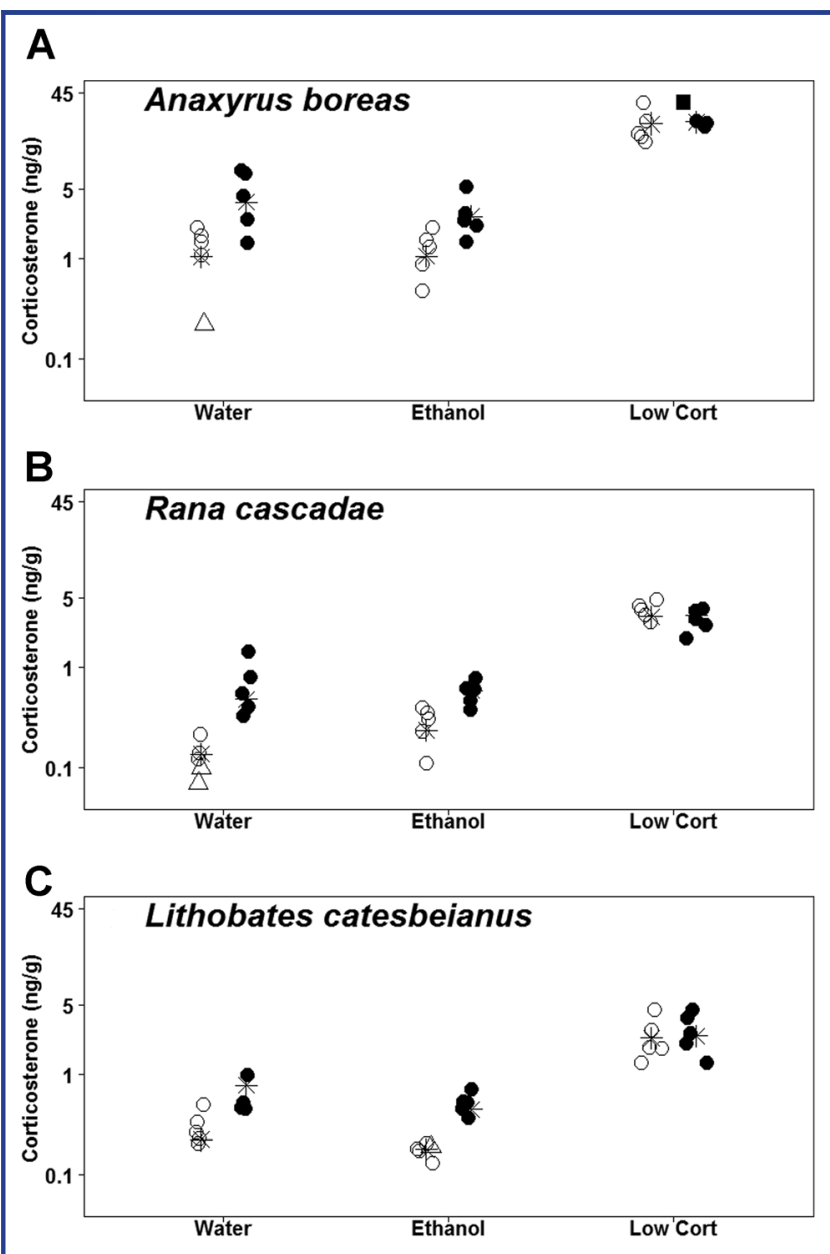

Figure 1. Whole-body corticosterone levels for (A) Anaxyrus boreas, (B) Rana cascadae, and (C) Lithobates catesbeianus as larvae (expt. 1). Closed symbols represent animals exposed to Batrachochytrium dendrobatidis $(\mathrm{Bd})$, while open symbols represent unexposed individuals. Circles represent completely observed data, squares represent right-censored "non-detects," and triangles represent left-censored "non-detects." Each star represents the predicted mean for the corresponding group of animals and data points are jittered horizontally to make them more distinguishable. While non-detects are plotted as if their concentration were exactly known, the analysis considered them as censored, and thus only known to be above or below their depicted concentration. The high corticosterone treatment was excluded from this analysis, as it contained too many censored values.

levels (Crespi and Denver, 2005). Thus, larval infection could indirectly cause increases in corticosterone by reducing food intake. Elevation of corticosterone from Bd occurred to a greater degree in the ethanol and water treatments (Fig. 1, Table S3), indicating that exogenous corticosterone exposure partially overwhelms the effects of corticosterone elevation from $\mathrm{Bd}$ in larvae. We also found that post-metamorphic amphibians experienced a decrease in corticosterone after $\mathrm{Bd}$ exposure. Thus there are stage-specific responses to infection. In amphibians, the immune and endocrine response varies greatly with life stage, so these differences may reflect the physiological differences among life stages. Our findings are in contrast to Peterson et al. (2013) who found that Bd infection increased corticosterone levels in post-metamorphic Litoria caerulea. However, this study used a different species and measured corticosterone after clinical signs of disease were present. Our post-metamorphic infections were relatively light and of a shorter duration than some other $\mathrm{Bd}$ studies (e.g., Carey et al., 2006; Searle et al., 2011a; Gervasi et al., 2013). Therefore, the effects of infectious disease on stress (and vice versa) may depend on life history stage, species, infection severity and infection duration.

Even though all species were exposed to the same corticosterone treatments, we found differences among species in resulting whole-body concentrations of corticosterone. Corticosterone levels in our control treatments were similar to levels found in field-collected amphibian larvae (Belden et al., 2005, 2010), indicating that our housing methods did not cause excessive stress to the animals. Anaxyrus boreas had the highest whole-body levels of corticosterone in all treatments while $L$. catesbeianus had the lowest levels. Variation among the two larval hormone assays could potentially contribute to this finding, as $A$. boreas samples were run separately from the other two species. However, this likely represents a real pattern since another study with chronic exposure to exogenous corticosterone (Belden et al., 2010), found that Eastern spadefoot toads (Scaphiopus holbrooki) on average had higher baseline levels of corticosterone than two other species (Rana sylvatica and Ambystoma jeffersonianum). Thus, it appears that toads may elevate their corticosterone levels to a greater degree compared to other groups of amphibians.

We also found differences among species in infection prevalence and severity at the larval stage. Lithobates catesbeianus had the highest infection prevalence of the three species, while $R$. cascadae had the highest infection severity (Table 1). We did not observed 100\% infection in any species, which is typical for experimental exposures of larvae to Bd (Venesky et al., 2010; Searle et al., 2011b; Gervasi et al., 2013). Since larvae can lose infection through time (Searle et al., 2013), it is possible that a higher percentage of our animals were infected immediately after Bd exposure, but lost infections before the end of the experiment. Therefore, differences in infection prevalence among species may represent differences in their ability to acquire infection or lose infection though time. Our patterns of infection severity are in contrast to previous studies that show $R$. cascadae with lower infection levels than co-occurring species (Searle et al., 2011b; Gervasi et al., 2013). Each of these studies used slightly different rearing and exposure conditions, indicating that among-species infection patterns may be context-dependent. 

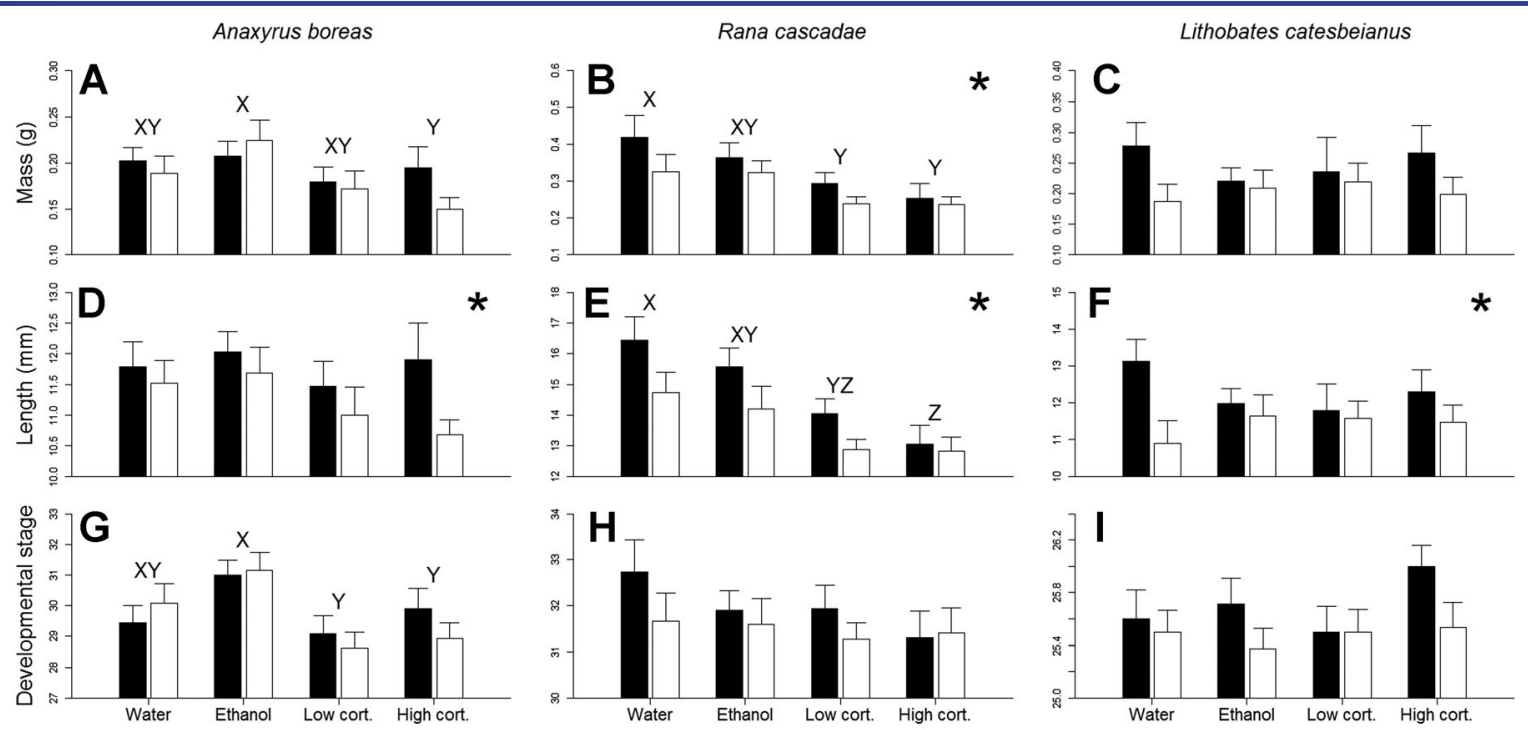

Figure 2. Effects of corticosterone and Batrachochytrium dendrobatidis (Bd) treatment on larval size and development (expt. 1). Panels show average (A) Anaxyrus boreas mass, (B) Rana cascadae mass, (C) Lithobates catesbeianus mass, (D) A. boreas length, (E) $R$. cascadae length, (F) L. catesbeianus length, $(\mathrm{G}) A$. boreas developmental stage, $(\mathrm{H}) R$. cascadae developmental stage, and (I) $L$. catesbeianus developmental stage (all $\pm \mathrm{SE}$ ). Length was determined by measuring the distance between the snout and vent on each animal and developmental stage was determined using Gosner ('60). White bars indicate unexposed treatments and dark bars represent treatments exposed to Bd. Differences among corticosterone treatments are indicated as different letters $(X, Y$, or $Z)$ where treatments containing similar letters do not differ according to Tukey's HSD tests. Stars indicate a significant effect of Bd exposure.

Life history characteristics may contribute to the observed differences in corticosterone levels and Bd infections. For example, one would expect that $L$. catesbeianus, which has a long larval period compared to the other species, would exhibit different patterns of corticosterone and infection as they are

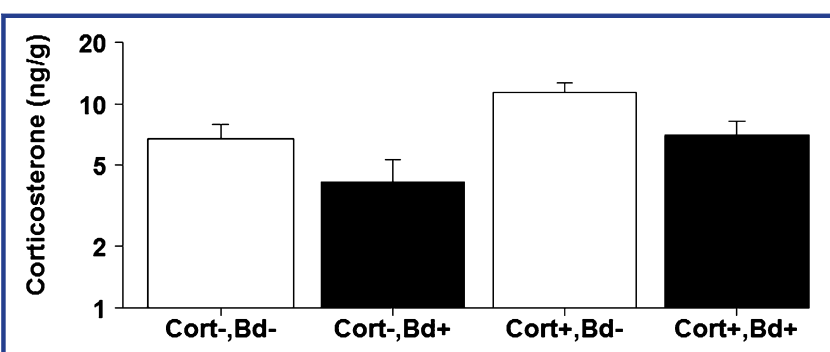

Figure 3. Predicted mean ( \pm SE) whole-body corticosterone content for post-metamorphic Rana cascadae (expt. 2). Treatments are shown as "Bd-" (in white) and "Bd+" (in black) to represent treatments unexposed or exposed to Batrachochytrium dendrobatidis $(\mathrm{Bd})$, respectively. "Cort-" or "Cort+" represent those unexposed and exposed to corticosterone, respectively. Exposure to corticosterone increased levels of corticosterone, while exposure to $\mathrm{Bd}$-decreased levels of corticosterone. in the pre-metamorphic stage for longer. This difference in life history could explain why L. catesbeianus size and development were unaffected by exposure to corticosterone and why this species had the lowest corticosterone levels. Further studies are necessary to understand how differences among species impact an animal's response to stressful conditions and pathogens.

We found that corticosterone exposure decreased mass and developmental stage in A. boreas larvae and decreased mass and length in $R$. cascadae larvae. This effect has been demonstrated in other amphibian species, where elevated levels of corticosterone decreased rates of growth and development at early larval stages (Hayes et al., '93; Glennemeier and Denver, 2002b). Thus, even if elevated corticosterone does not directly alter infection, it can still affect amphibian larvae by altering growth and development. In $L$. catesbeianus, growth and development was unaffected by corticosterone, but this species also had the lowest concentrations of corticosterone compared to the two other species. Lithobates catesbeianus also had higher infection prevalence than the other two species and can survive with high levels of infection (Daszak et al., 2004; Blaustein et al., 2005). This combination of high tolerance and ease at acquiring Bd indicates that $L$. catebeianus may be particularly competent hosts to act as reservoirs for $\mathrm{Bd}$. 
In all species, larvae exposed to Bd were longer at the end of the experiment than unexposed individuals. Since we did not see a difference in mortality with Bd infection, this finding is not the result of Bd killing the smallest, weakest larvae and leaving only the larger animals in the $\mathrm{Bd}$-exposed treatments. When larval amphibians are infected with $\mathrm{Bd}$, their mouthparts are affected, reducing feeding rates in some species (Venesky et al., 2010). Therefore, it is generally believed that $\mathrm{Bd}$ infection will slow growth and development in larval amphibians. However, if food is readily available, larvae may increase growth rates in response to the presence of zoospores as an attempt to speed development and exit water bodies containing Bd. Amphibian larvae can alter developmental rates in response to many factors including pond drying and predation (Werner, '86; Semlitsch and Wilbur, '88). Therefore, even though we did not see an increase in developmental rate with $\mathrm{Bd}$ exposure, increasing body size may help prepare for a reduced time to metamorphosis to exit locations where pathogens are present.

Based on our results, elevated levels of corticosterone do not influence larval or post-metamorphic amphibian susceptibility to $\mathrm{Bd}$. This supports previous studies in amphibians that have also failed to detect a link between stress and increased susceptibility to disease (e.g., Haislip et al., 2012; Reeve et al., 2013). However, even though exposure to exogenous corticosterone did not increase infection in our study, environmental changes may still alter Bd dynamics by affecting other aspects of the amphibian-Bd relationship such as transmission, reproductive rates, recovery rates, and host mortality. Our study demonstrates that a link between elevated levels of corticosterone and disease susceptibility cannot be assumed in all cases. In general, the interactions between environmental change, stress hormones and infectious diseases are complex and not well understood. The role of physiological stress in altering disease dynamics appears to be more complex than can be explained simply through single stress measurements.

\section{ACKNOWLEDGMENTS}

We would like to thank S. Gervasi, M. Christie, L. Cha, A. Husain, J. Spatafora, E. Borer, J. Bartholomew, W. Stubblefield, and M. Cook for their assistance with this project. This project was supported by funding from a Graduate Women in Science Sigma Delta Epsilon Fellowship to C.L.S., the Society of Wetland Scientists, the Environmental Sciences Graduate Program at Oregon State University, and National Science Foundation grant DEB0918960 to L.K.B. This study was conducted in accordance with Oregon State University's Institutional Animal Care and Use Committee (permit \#3553).

\section{LITERATURE CITED}

Anderson PK, Cunningham AA, Patel NG, et al. 2004. Emerging infectious diseases of plants: pathogen pollution, climate change and agrotechnology drivers. Trends Ecol Evol 19:535-544.
Belden LK, Kiesecker JM. 2005. Glucocorticosteroid hormone treatment of larval treefrogs increases infection by Alaria sp. trematode cercariae. J Parasitol 91:686-688.

Belden LK, Moore IT, Mason RT, Wingfield JC, Blaustein AR. 2003. Survival, the hormonal stress response and UV-B avoidance in Cascades Frog tadpoles (Rana cascadae) exposed to UV-B radiation. Funct Ecol 17:409-416.

Belden LK, Moore IT, Wingfield JC, Blaustein AR. 2005. Corticosterone and growth in Pacific treefrog (Hyla regilla) tadpoles. Copeia 2:424430.

Belden LK, Wingfield JC, Kiesecker JM. 2010. Variation in the hormonal stress response among larvae of three amphibian species. J Exp Zool A Ecol Genet Physiol 313:524-531.

Berger L, Speare R, Daszak P, et al. 1998. Chytridiomycosis causes amphibian mortality associated with population declines in the rain forests of Australia and Central America. Proc Natl Acad Sci USA 95:9031-9036.

Blaustein AR, Romansic JM, Scheessele EA, et al. 2005. Interspecific variation in susceptibility of frog tadpoles to the pathogenic fungus Batrachochytrium dendrobatidis. Conserv Biol 19:1460-1468.

Boyle DG, Boyle DB, Olsen V, Morgan JAT, Hyatt AD. 2004. Rapid quantitative detection of chytridiomycosis (Batrachochytrium dendrobatidis) in amphibian samples using real-time Taqman PCR assay. Dis Aquat Organ 60:141-148.

Carey C, Bruzgul JE, Livo $\sqcup$, et al. 2006. Experimental exposures of boreal toads (Bufo boreas) to a pathogenic chytrid fungus (Batrachochytrium dendrobatidis). EcoHealth 3:5-21.

Chambers DL, Wojdak JM, Du P, Belden LK. 2011. Corticosterone level changes throughout larval development in the amphibians Rana sylvatica and Ambystoma jeffersonianum reared under laboratory, mesocosm, or free-living conditions. Copeia 4:530-538.

Chambers DL, Wojdak JM, Du P, Belden LK. 2013. Pond acidification may explain differences in corticosterone among salamander populations. Physiol Biochem Zool 86:224-232.

Cohn L. 1997. Glucocorticoids as immunosuppressive agents. Semin Vet Med Surg Small Anim 12:150-156.

Crawley MJ. 2007. The R book. West Sussex, UK: John Wiley \& Sons.

Crespi EJ, Denver RJ. 2005. Roles of stress hormones in food intake regulation in anuran amphibians throughout the life cycle. Comp Biochem Physiol A Mol Integr Physiol 141:381-390.

Cyr NE, Romero LM. 2007. Chronic stress in free-living European starlings reduces corticosterone concentrations and reproductive success. Gen Comp Endocrinol 151:82-89.

Cyr NE, Earle K, Tam C, Romero LM. 2007. The effects of chronic psychological stress on corticosterone, plasma metabolites, and immune responsiveness in European starlings. Gen Comp Endocrinol 15:59-66.

Daszak P. 2000. Emerging infectious diseases of wildlife-threats to biodiversity and human health. Science 287:443-449.

Daszak P, Cunningham AA, Hyatt AD. 2001. Anthropogenic environmental change and the emergence of infectious diseases in wildlife. Acta Trop 78:103-116. 
Daszak P, Strieby A, Cunningham AA, et al. 2004. Experimental evidence that the bullfrog (Rana catesbeiana) is a potential carrier of chytridiomycosis, an emerging fungal disease of amphibians. Herpetol J 14:201-208.

Davis AK, Keel MK, Ferreira A, Maerz JC. 2010. Effects of chytridiomycosis on circulating white blood cell distributions of bullfrog larvae (Rana catesbeiana). Comp Clin Pathol 19:49-55.

Denver RJ. 1997. Environmental stress as a developmental cue: corticotrophin-releasing hormone is a proximate mediator of adaptive phenotypic plasticity in amphibian metamorphosis. Horm Behav 31:169-179.

Dhabhar FS. 2000. Acute stress enhances while chronic stress suppresses skin immunity: the role of stress hormones and leukocyte trafficking. Ann N Y Acad Sci 917:876-893.

Dunlap KD, Schall JJ. 1995. Hormonal alterations and reproductive inhibition in male fence lizards (Sceloporus occidentalis) infected with the malarial parasite Plasmodium mexicanum. Physiol Zool 68:608-621.

Dunn AJ, Powell ML, Meitin C, Small PA Jr. 1989. Virus infection as a stressor: influenza virus elevates plasma concentrations of corticosterone, and brain concentrations of MHPG and tryptophan. Phyiol Behav 45:591-594.

French SS, McLemore R, Vernon B, Johnston GIH, Moore MC. 2007. Corticosterone modulation of reproductive and immune system trade-offs in female tree lizards: long-term corticosterone manipulations via injectable gelling material. J Exp Biol 210: 2859-2865.

Gabor CR, Fisher MC, Bosch J. 2013. A non-invasive stress assay shows that tadpole populations infected with Batrachochytrium dendrobatidis have elevated corticosterone levels. PLoS ONE 8:e56054.

Garcia TS, Romansic JM, Blaustein AR. 2006. Survival of three species of anuran metamorphs exposed to UV-B radiation and the pathogenic fungus Batrachochytrium dendrobatidis. Dis Aquat Organ 72:163-169.

Gervasi S, Gondhalekar C, Olson DH, Blaustein AR. 2013. Host identity matters in the amphibian-Batrachochytrium dendrobatidis system: fine-scale patterns of variation in response to a multi-host pathogen. PLoS ONE 8:e54490.

Glennemeier KA, Denver RJ. 2002a. Developmental changes in interrenal responsiveness in anuran amphibians. Integr Comp Biol 42:565-573.

Glennemeier KA, Denver RJ. 2002b. Small changes in whole-body corticosterone content affect larval Rana pipiens fitness components. Gen Comp Endocrinol 127:16-25.

Glennemeier KA, Denver RJ. 2002c. Role for corticoids in mediating the response of Rana pipiens tadpoles to intraspecific competition. J Exp Zool 292:32-40.

Gosner KL. 1960. A simplified table for staging anuran embryos and larvae with notes on identification. Herpetologica 16:183-190.

Haislip NA, Hoverman JT, Miller DL, Gray MJ. 2012. Natural stressors and disease risk: does the threat of predation increase amphibian susceptibility to ranavirus? Can J Zool 90:893-902.
Harris RN, James TY, Lauer A, Simon MA, Patel A. 2006. Amphibian pathogen Batrachochytrium dendrobatidis is inhibited by the cutaneous bacteria of amphibian species. EcoHealth 3:53-56.

Harvell CD, Mitchell C, Ward J, et al. 2002. Climate warming and disease risks for terrestrial and Marine Biota. Science 296:21582162.

Hayes TB. 1997. Steroids as potential modulators of thyroid hormone activity in anuran metamorphosis. Integr Comp Biol 37:185-194.

Hayes $T$, Chan R, Licht P. 1993. Interactions of temperature and steroids on larval growth, development, and metamorphosis in a toad (Bufo boreas). J Exp Zool 266:206-215.

Hayes T, Case P, Chui S, et al. 2006. Pesticide mixtures, Endocrine disruption, and amphibian declines: Are we underestimating the impact? Environ Health Perspect 114:S40-S50.

Helsel DR. 2005a. Non-detects and data analysis: statistics for censored environmental data. New York: John Wiley \& Sons.

Helsel DR. 2005b. More than obvious: better methods for interpreting nondetect data. Environ Sci Technol 39:419A-423A.

Hopkins WA, Mendonca MT, Congdon JD. 1999. Responsiveness of the hypothalamo-pituitary-interrenal axis in an amphibian (Bufo terrestris) exposed to coal combustion wastes. Comp Biochem Physiol C Phamacol Toxicol Endocrinol 122:191-196.

Janin A, Lena JP, Joly P. 2011. Beyond occurrence: body condition and stress hormones as integrative indicators of habitat availability and fragmentation in the common toad. Biol Conserv 144: 1008-1016.

Jones KE, Patel NG, Levy MA, et al. 2008. Global trends in emerging infectious diseases. Nature 451:990-993.

Kent RW, Funk JR. 2004. Data censoring and parametric distribution assignment in the development of injury risk function from biomechanical data. SAE Technical Paper 2004-01-0317.

Kiank C, Holtfreter B, Starke A, et al. 2006. Stress susceptibility predicts the severity of immune depression and the failure to combat bacterial infections in chronically stressed mice. Brain Behav Immun 20:359-368.

Kloas W, Reinecke M, Hanke W. 1997. Stage-dependent changes in adrenal steroids and catecholamines during development in Xenopus laevis. Gen Comp Endocr 108:416-426.

Kostelanetz S, Dickens MJ, Romero LM. 2009. Combined effects of molt and chronic stress on heart rate, heart rate variability, and glucocorticoid physiology in European Starlings. Comp Biochem Physiol A Mol Integr Physiol 154:493-501.

Lam BA, Walke JB, Vredenburg VT, Harris RN. 2010. Proportion of individuals with anti-Batrachochytrium dendrobatidis skin bacteria is associated with population persistence in the frog Rana muscosa. Biol Conserv 143:529-531.

Longcore JE, Pessier AJ, Nichols DK. 1999. Batrachochytrium dendrobatidis gen. et sp. nov., a chytrid pathogenic to amphibians. Mycologia 91:219-227.

Marantelli G, Berger L, Speare R, Keegan L. 2004. Distribution of the amphibian chytrid Batrachochytrium dendrobatidis and keratin during tadpole development. Pac Conserv Biol 10:173-179. 
Martin LB, Gilliam J, Han P, Lee K, Wikelski M. 2005. Corticosterone suppresses cutaneous immune function in temperate but not tropical House Sparrows, Passer domesticus. Gen Comp Endocrinol 140:126-135.

Martin LB, Hopkins WA, Mydlarz LD, Rohr JR. 2010. The effects of anthropogenic global changes on immune functions and disease resistance. Ann N Y Acad Sci 1195:129-148.

Moore FL, Miller $\sqcup$. 1984. Stress-induced inhibition of sexual behavior: corticosterone inhibits courtship behaviors of a male amphibian (Taricha granulosa). Horm Behav 18:400-410.

Norris DO, Donahue S, Dores RM, et al. 1999. Impaired adrenocortical response to stress by brown trout, Salmo trutta, living in metalcontaminated waters of the Eagle River, Colorado. Gen Comp Endocrinol 113:1-8.

Patz JA, Graczyk TK, Geller N, Vittor AY. 2000. Effects of environmental change on emerging parasitic diseases. Int J Parasitol 30:13951405.

Peterson JD, Peterson VA, Mendonça MT. 2009. Exposure to coal combustion residues during metamorphosis elevates corticosterone content and adversely affects oral morphology, growth, and development in Rana sphenocephala. Comp Biochem Physiol C Toxicol Pharmacol 149:36-39.

Peterson JD, Steffen JE, Reinert LK, et al. 2013. Host stress response is important for the pathogenesis of the deadly amphibian disease, chytridiomycosis, in Litoria caerulea. PLoS ONE 8:e62146.

R Development Core Team. 2011. R: a language and environment for statistical computing. Vienna, Austria: R Foundation for Statistical Computing. ISBN 3-900051-07-0. Available online at: http://www. R-project.org/

Ramsey JP, Reinert LK, Harper LK, Woodhams DC, Rollins-Smith LA. 2010. Immune defenses against Batrachochytrium dendrobatidis, a fungus linked to global amphibian declines in the South African clawed frog, Xenopus laevis. Infect Immun 78:3981-3992.

Raouf SA, Smith LC, Brown MB, Wingfield JC, Brown CR. 2006. Glucocorticoid hormone levels increase with group size and parasite load in cliff swallows. Anim Behav 71:39-48.

Reeve BC, Crespi EJ, Whipps CM, Brunner JL. 2013. Natural stressors and ranavirus susceptibility in larval wood frogs (Rana sylvatica). EcoHealth 10:190-200.

Ribas L, Li MS, Doddington BJ, et al. 2009. Expression profiling the temperature-dependent amphibian response to infection by Batrachochytrium dendrobatidis. PLoS ONE 4:e8408.

Rollins-Smith LA, Blair PJ. 1993. The effects of corticosteroid hormones and thyroid hormones on lymphocyte viability and proliferation during development and metamorphosis in Xenopus laevis. Differentiation 54:155-160.

Rollins-Smith LA, Carey C, Longcore JE, et al. 2002. Activity of antimicrobial skin peptides from ranid frogs against Batrachochytrium dendrobatidis, the chytrid fungus associated with global amphibian declines. Dev Comp Immunol 26:471-479.
Romero LM. 2002. Seasonal changes in plasma glucocorticoid concentrations in free-living vertebrates. Gen Comp Endocrinol 128:1-24.

Romero LM, Wikelski M. 2010. Stress physiology as a predictor of survival in Galapagos marine iguanas. Proc R Soc Lond B Biol Sci 277:3157-3162.

Romero LM, Dickens MJ, Cyr NE. 2009. The reactive scope model-a new model integrating homeostasis, allostasis, and stress. Horm Behav 55:375-389.

Rosenblum EB, Poorten TJ, Settles M, et al. 2009. Genome-wide transcriptional response of Silurana (Xenopus) tropicalis to infection with the deadly chytrid fungus. PLoS ONE 4:e6494.

Searle CL, Gervasi SS, Hua J, et al. 2011a. Differential host susceptibility to Batrachochytrium dendrobatidis, an emerging amphibian pathogen. Conserv Biol 25:965-974.

Searle CL, Biga LM, Spatafora JW, Blaustein AR. 2011b. A dilution effect in the emerging amphibian pathogen Batrachochytrium dendrobatidis. Proc Natl Acad Sci USA 108:16322-16326.

Searle CL, Xie GY, Blaustein AR. 2013. Development and infectious disease in hosts with complex life cycles. PLoS ONE 8: e60920.

Semlitsch R, Wilbur H. 1988. Effects of pond drying time on metamorphosis and survival in the salamander, Ambystoma talpoideum. Copeia 4:978-983.

Stice MJ, Briggs CJ. 2010. Immunization is ineffective at preventing infection and mortality due to the amphibian chytrid fungus, Batrachochytrium dendrobatidis. J Wildl Dis 46:70-77.

Tilbrook AJ, Turner Al, Clarke IJ. 2000. Effects of stress on reproduction in non-rodent mammals: the role of glucocorticoids and sex differences. Rev Reprod 5:105-113.

Venesky MD, Parris MJ, Storfer A. 2010. Impacts of Batrachochytrium dendrobatidis infection on tadpole foraging performance. EcoHealth 6:565-575.

Venesky MD, Wilcoxen $T E$, Rensel MA, et al. 2012. Dietary protein restriction impairs growth, immunity, and disease resistance in southern leopard frog tadpoles. Oecologia 169:23-31.

Warne RW, Crespi EJ, Brunner JL. 2011. Escape from the pond: stress and developmental responses to ranavirus infection in wood frog tadpoles. Funct Ecol 25:139-146.

Werner E. 1986. Amphibian metamorphosis: growth rate, predation risk, and the optimal size at transformation. Am Nat 128: 319-341.

Woodhams DC, Vredenburg VT, Simon MA, et al. 2007. Symbiotic bacteria contribute to innate immune defenses of the threatened mountain yellow-legged frog, Rana muscosa. Biol Conserv 138:390-398.

\section{SUPPORTING INFORMATION}

Additional Supporting Information may be found in the online version of this article at the publisher's web-site. 